\title{
Self-executing Contracts from the perspective of the selected Polish regulations and the future potential prevalence of 'Smarter' Contracts
}

\author{
Rafal Tomasz Prabucki \\ Centre for Legal Problems of Technical Issues and New Technologies, University of Opole, Poland
}

Correspondence: rprabucki@uni.opole.pl

Received: 24 February 2020 Accepted: 15 April 2020 Published: 30 April 2020

\begin{abstract}
For some time now, blockchain technology has been used for many purposes all over the world. The question arises - how do we regulate proving facts in a dispute between agreement parties when they use self-executing contracts? The answer to this question is explored in this research in the context of civil issues. Furthermore, the Polish law has introduced a new tool in the form of a 'contract of evidence' (similar to the parol evidence rule) which may increase the popularity of smart contracts. The research methodology is based on the analysis of the two existing regulations from the Civil Procedure Code and the Commercial Code. Moreover, legal scientific studies that indicate the risks associated with using self-executing contracts in such a way will be analysed. All efforts have been taken to obtain conclusions regarding the future of this type of solution in Poland and Polish smart cities.
\end{abstract}

Keywords: contract of evidence, Polish law, blockchain, smart contracts, evidence law

JEL Classifications: K10, K12, K15, K20, K24, K40

\section{Introduction and methodology}

For the last few years, smart contracts have become the subject of increasing interest of political decision-makers, among others, who obviously show strong interest in this kind of novelty, but what is more important in this case is that, at the same time, they are undertaking the necessary measures to introduce legal regulations connected with it. The Polish Institute of Justice has commissioned a scientific report which, despite the fact that it does not directly address the issue of the idea of smart contracts, indicates, due to the questions related to blockchain technology, that such an element of development of this technology exists and is a subject of interest of legislators of various countries. The analysis of sources cited for the purpose of this report shows that at least four European countries have presented concrete proposals for legal definitions for this concept. In the United States, in turn, at least four states have developed new juridical categories, including smart contracts [1].

Such a keen interest of policy makers in this matter should not come as a surprise. Scientific debates, which include the word "smart contract", are not limited only to areas such as mathematics, computing and engineering but also covered the fields connected with energy and social science discussions. The countries that are at the forefront of scientific publications on smart contracts are first and foremost the ones which have officially developed or are observing and planning to develop a possible kind of regulation for the blockchain industry. Among these are countries such as the United States, China, the Russian Federation, South Korea and the United Kingdom. Poland is not listed [2].

This work aims at catching up on this issue by drawing attention to the recent amendment to the Civil Code, which introduced a contract of evidence into Polish law. In accordance with the recommendations appearing in the literature dealing with the issue of smart contracts, the work first of all assumes the approximation of the diversity of approaches in defining smart contracts.

\section{Theoretical foundations of smart contracts and links to blockchain}

The original source of knowledge about smart contracts are works from the 1990s. Thanks to Nick Szabo, his essays and scientific papers, the term "smart contract" has penetrated the legal world. This is not the only issue that should be brought closer to the work of a computer scientist and lawyer. Szabo also refers to the so-called "micropayments" in his works. Both phrases were supposed to help outline the predicted changes in the law of obligations, which were to appear and spread due to technological progress. The Internet, through its protocols, revolutionised the 
transmission of information across the globe. It has become possible to draw up a theoretical protocol for the declarations of will and knowledge that make up the agreement. N. Szabo defines smart contract as "Smart contract is a computerised transaction protocol that executes the terms of a contract". Furthermore, he added that "the general objectives are to satisfy common contractual conditions (such as payment terms, liens, confidentiality, and even enforcement), minimize exceptions both malicious and accidental, and minimize the need for trusted intermediaries. Related economic goals include lowering fraud loss, arbitrations and enforcement costs, and other transaction costs" [3].

The second element, which is very significant, contains micropayments. For their application, N. Szabo identified specific markets, such as the electricity market, where complicated contracts and the need for constant invoicing are major problems. In the context of micropayments, however, the researcher refers to intelligent agents [4]. Vincenzo Morabito notes that there is, in the context of their theoretical assumptions, a lot of convergence between smart agents derived from the concept of software agents and smart contracts and there is even a convertible application of both concepts. These coincidences also strongly emphasise the modern relationship of smart contracts with Distributed Ledger Technology (DLT), which has the potential to facilitate business models based on micropayments [5]. It is necessary to mention that the dissemination of the idea of smart contracts occurred after the launch of bitcoin, the first cryptocurrency. Moreover, Vitalik Buterin added an opportunity to his idea of cryptocurrency, which is the possibility of creating smart contracts in blocks. The language in which it could be created was the programming language of Solidity. Blockchain of this type was called the "new generation", due to the implementation of the virtual machine. The Ethereum not only recorded the information about the trading of transactions of Ether (payments token) but also enabled creating computer programs which were aimed to automate this kind of trading. BT allowed to secure smart contracts accordingly. Furthermore, when smart contracts are recorded in blocks of chains, they are difficult either to sabotage or to edit the conditions they contain. G. Wood, co-founder of Ethereum, called this: "a general implementation of such a crypto-law system" $[6,7,8,9,10,11]$.

\section{DLT and smarter contracts}

However, smart contracts in the Ethereum blockchain are not free from defects and certain restrictions. Working in this environment is based on careful selection of programming code due to the fee for using a virtual machine with a token called "Gas". In consequence, the price that must be paid for purchasing Ethereum tokens can make creating certain smart contracts unprofitable. It is not only about the price of the Ether token but also about the number of Gas tokens that have to be paid to run the program [6]. Moreover, it should be emphasised that participation in an open blockchain is allowed to anyone. So it may happen that dishonest persons may appear or even smart contracts can be created to secure parties who have contracted a service which is classified as a criminal offence in a given legal system.

However, smart contracts are also possible to be carried out in closed blockchain solutions as well as blockchain-like solutions (e.g. Corda), which can be easily entered within the name range of DLT. New technological possibilities and solutions also increase the range of possible combinations in terms of operation. Rory Unsworth proposes to add the term "smarter contracts" to the scientific discussion and suggests that this term includes split and hybrid smart contract models. The author of this classification also emphasises that "smarter" is not related to the fact that these solutions are better, as the ones described by N. Szabo equally qualify for this name. In order to define smarter contracts, it is necessary to call them self-executing contracts. The hybrid model adds human factor as supervising the operation of the contract in certain situations. The split model, on the other hand, serves to combine certain expressions of language, which is understandable to people but also connects with the activities of a smart contract. These concepts expand the business application of the individual models and order the chaos in theoretical deliberations on the law and the future of selfexecuting contracts $[12,13,14]$.

It is also important to signal that the flywheel of self-executing contracts is the incoming data, which triggers subsequent elements of the contract after the relevant facts have occurred. Collecting important information from outside the blockchain is possible due to connectors called "Oracles" [15].

It seems that it is the possibility to collect data that puts selfexecuting contracts high in the hierarchy of essential elements that will shape our world in the era of the Internet of Everything (IoE). The future that awaits us will surely also bring a question about where the data for self-executing contracts are drawn from and whether they can be trusted. However, before this happens, it is important to pay attention to certain possibilities and issues concerning obstacles of legal nature [15].

It should not be forgotten that a contract is still - in the traditional sense - not only a set of commitments but also a scenario designed according to certain regulations with mechanisms that are adapted to certain situations [16].

\section{Contract automation in Polish legal scholarship}

N. Szabo, in his theory, compares smart contracts to vending machines. In the Polish school of academic thought, this problem was raised by Ernest Till in 1900. According to these general demands, vending machines are an offer addressed to the general public. Due to the lack of words or letters, the whole state of affairs can be considered as the content. The conclusion of a contract occurs when both parties correctly demonstrate their willingness to join through appropriate behaviour. an inserted coin generates the information for the 
exhibitor of the vending machine of joining the offer by the other party. When it comes to smart contracts, the transfer of the relevant token(s) will be considered as silent provision of services, which the creator of the smart contract has required. This moment will be considered as a contract entry. It is worth noticing that the difference between displaying such articles as, e.g., newspapers and bread in front of the shop and a vending machine was also noticed. In the former case, E. Till emphasises that a person coming up with an offer, that is, a bidder, gives himself a certain freedom in order to secure his right to make decisions on the execution of the contract. As in the case of the hybrid model, there still remains some scope for human action [17].

It probably never occurred to E. Till that similar mechanisms would appear on the line of much more complicated contracts. That is why Robert Herian calls the vending machine theory "elegant", but he criticises it for the probability of a defect occurrence, meaning that it looks well until it works without problems [15].

A contemporary concept of smart contracts in Polish legal scholarship is presented by Dariusz Szostek. His approach is based on a list of legal definitions from other countries and their comparison. The author draws attention to three examples from Malta, Belarus and the state of Arizona. As the most advanced, mature and adequate to the technical reality, D. Szostek indicates the definition which was constructed for the needs of Maltese law. According to this definition "smart contract" means a form of innovative technology arrangement consisting of: (a) a computer protocol and/or (b) an agreement concluded entirely or partly in an electronic form, which is automatable and enforceable by the execution of computer code, although some parts may require human input and control and which may also be enforceable by ordinary legal methods or by a mixture of both [18].

In terms of the technical and theoretical elements of smart contracts cited above, the legislator's approach in such a direction as to take account of the issues of computer protocols and the electronic nature of the contract, together with a general outline of some of its features, shows a high degree of sophistication and is a sign of maturity. In both examples presented by D. Szostek - the one of the state of Arizona and another one of Belarus - references to BT and DLT terminology dominated. The use of blockchain-related concepts complicates the definition unnecessarily, making it incomprehensible to a person who does not deal with it on a daily basis. Moreover, a strong reference to the medium seems to be a significant limitation in the creation of this technology in the future $[13,18,19]$.

The choice of D. Szostek expands the debate about smart contracts. The Maltese legal definition has several significant advantages:

- It emphasises the aspect of the legal act and the means of electronic communication, not the medium.
- It leaves space for the split and hybrid models.

- It proposes an additional scope of the name which does not refer to the term of the contract.

Moreover, the definition of diversity of the use of smart contracts is that it creates a technological neutrality, which can be adopted and put into long-term use without changes to this jury category. The Maltese legislator does not use the terminology which is characteristic for DLT; what is more, the Maltese legislator proposes two concepts of smart contract, one of these is not related to the sphere of obligations. As a result, a scenario in which a smart contract can appear in the state's actions is not excluded but is taken into consideration; at the same time, a new situation is created in which smart contracts can appear in an entirely different sphere, that is, in the sphere of public authority.

In the first place, the smarter contracts and its further development will have a significant impact on the civil law sphere. It should be noted that two main points are specified within the civil law sphere according to the European Union (EU) report and these are as follows [20]:

- Smart legal contracts are smart contracts on a blockchain that represent - or that would like to represent - a legal contract, along with the issues that are involved.

- Smart contracts with legal implications are artefacts/constructs based on smart technologies that clearly have legal implications.

Therefore, it should not come as a surprise that the emergence of self-executing contracts in practice implies not only the need to create legal definitions but also changes in other legal acts. The problem is not only the legal framework of a certain relationship in which a program written in programming code may not fit but also the programming language and the way in which certain processes work, as these are the factors which the court may not understand. Moreover, it should be assumed that some changes still appear as new ones in numerous works and approach to smart contracts (jellyfish theory). It is also important to point out that not only the consequences of the regulations being created are important but also unplanned changes that are difficult to predict $[9,12$, $13,15]$.

\section{Legislative tendencies and Polish regulations}

The emergence of smart contracts is causing various reactions of law-making nature worldwide. Mainly the acts of BT regulation are introduced, but the example of the Russian Federation shows that changes are constantly made to legislative acts. Russia, like other progressive countries, has created a legal definition of smart contracts as well. The content of this definition in full wording is as follows: "an electronic contract, whose rights and obligations are executed automatically in a distributed register of digital transactions in 
a sequence strictly defined by such a contract and after the circumstances have occurred" $[1,21]$.

The introduction of this juridical concept into the Russian legal system has resulted in changes to the Civil Code. It not only did add many elements such as "Internet", "electronic" and "digital", but the section on contracts was extended with a new paragraph: "A contract may provide for the performance of an obligation under the contract after certain circumstances have occurred which were not covered by the will of the party, but were defined at the time of the conclusion of the contract by the terms of the transaction concluded in an information system (automated performance). Only the parties to the agreement may call for the performance of such an obligation". This content indicates that it was created to secure the most important element of self-executing contracts - automation. The legislator has thus introduced a new optional element of the contract - automated performance of an obligation [1, 21-23].

Another example of solution is the one called "Singapore". In this case, the legislator amended the Evidence Law Act. Although the name of the concept of smart contract is not mentioned at all, there is a definition of electronic recording. In addition, the institution of presumptions in relation to electronic records was created, and the main purpose of this kind of legal institution is to instruct the court how to evaluate evidence [24].

In Poland, despite the proposal of amendment of the Commercial Companies Code and the introduction of DLT by introducing a clause in joint-stock companies and stock companies that "the register of shareholders is maintained in an electronic form, which may take the form of a distributed and decentralized database", as it can be used in running the company, which will imply proving certain facts in the future with the need to refer to DLT elements, including what smart contracts are and what they are meant for. In the case of tokenisation, the question of a "document" also arises [25]. In general, the court will have to check whether the solution used in the DLT can be treated as a document. Additionally, the court will also be obliged to verify in which DLT solution the data was saved. This issue of legal value blockchain will need to be examined based on eIDAS regulations [20].

No simultaneous attempt has been made in Poland in order to amend the Civil Code or the Civil Procedure Code. At present, there is no separate act in Poland which would regulate the issues of the law of evidence. It is worth noticing that for the period of time that self-executing contracts started to become more and more popular, there has been a change introduced in the Polish legal system affecting the practice of using smart contracts. It is the contract of evidence that is similar to the common law parol evidence rule.

\section{Contract of evidence}

A new institution in Polish law, based on parol evidence law, was established, and it can be presented in the following points [26]:
- It refers to the contractual relationship.

- It is addressed to entrepreneurs.

- It excludes certain means of proof.

In the context of the consideration of a smart contract, this judicial institution does not permit any agreement that restricts the court's ability to admit evidence or any possibility that could impose its assessment. As a result, it is neither possible to create new, and especially unknown to the procedural law, means (sources) and methods of evidence nor can specific evidence, special evidentiary power or any other extraordinary procedural significance be given priority. It is also not allowed to change the function of factual and legal presumptions and other rules of taking evidence. In conclusion, the parties cannot influence the free assessment of evidence [26].

Taking other aspects into account, it should be noted that the permitted exclusion of evidence may consist in prohibiting the use of certain types of evidence (e.g. evidence from witness statements, expert opinions, documents, etc.) or specific evidence, individualised by their exact description (e.g. evidence from a specific document, from specific witnesses, from specific expert opinions, etc.). The exclusion may also depend on the ban on proving specific circumstances, as, e.g., specific facts that normally are subject to the statement of the court (subject of evidence) [26].

So there are elements that can be used in the context of this institution and smart contracts. Knowing a specific expert, who, in his opinions, is not very reliable in presenting the issues of our smart contract; nothing stands in the way of excluding him by means of a contract of evidence; it can be orally submitted before the court. It is not possible to instruct the court to use, for example, the presumption of electronic recording, as presented above, by means of this evidence contract. The very limited institution of parol evidence law under Polish law seems to be neither particularly restrictive nor particularly supportive of the development of the use of smart contracts. It is possible that further adoption of the patterns of Anglo-American solutions will result in the appearance of new models. This situation seems more than likely as the entry into the IoE era will generate the need to expand this institution.

\section{Smart city in Poland and smart(er) contracts}

IoE is an important element of the difficult-to-define concept of the smart city, where in a nutshell, ubiquitous technology makes life easier for the digital society. It is worth underlining that the "smart" element of this concept, i.e. technology, may have undesirable consequences in the sphere of contracts for the legal awareness of smart city residents. The point is that people may not understand if and when they create legally binding contracts, or they may not understand their rights and obligations under their contracts. Technology saturation also depends on experts. Therefore, it seems reasonable to appeal to scientists for smart solutions, which will also be user- 
friendly and will take into account the dominant role of law in the sphere of contracts [23, 27].

There is also an important comment to be made in this area. Kevin Werbach and Nicolas Cornell noticed that selfexecuting contracts shift the focus of the remedy from execution to return [27]. However, it remains an open question whether it is a smart contract or a modern civil law turnover, with its tendency to accelerate access to, e.g., a service which implies an approach that gravity of the remedy is shifted. What really seems to change due to smarter contracts is definitely increasing formalism. The open question is how it will relate to human mess and human mistakes. Even in the most developed society functioning in a very advanced smart city, this problem will never be eliminated [27, 29].

In the context of the smart problem and technology-saturated contracts in terms of the smart city, there are also several other problems which are very significant:

- The development of smart contracts in a smart city requires a discussion about the adherent way of entering into contracts, which seems to be the natural direction in the sphere of citizen's activity in the city (entering the public transport vehicle, parking in the paid parking zone etc.)[29].

- Due to the international character of various corporations that offer smart contracts, the role of international private law, as well as establishing the proper international jurisdiction of the contract, seems to be very important [27, 30].

- The concepts of machine-to-machine contracts and the role of man who drives, for example, an autonomous electric vehicle that needs recharging batteries once in a while are also still discussed.

At the moment of writing the article in Poland, the authorities of one of the voivodeships officially admitted that they use DLT solutions. After preparing and submitting a request for access to public information to the Marshal's Office of the Warmińsko-Mazurskie voivodeships, a representative of the authorities has admitted that they use utility tokens called "CoperniCoin", which are assigned to the Waves token. The representative denied that the process of issuing took place in the framework of smart contracts and that smart contracts were used in the framework of CoperniCoins trading. Moreover, he noted that it is the designated employee who distributes the tokens as part of the region's promotional activities and that, until 18 December 2019, 101 CoperniCoin tokens were in circulation. Due to the lack of a legal definition of smart contracts, it is difficult to question or criticise such an approach, and it should be considered as correct. However, it is the irrefutable evidence that the popularity of DLT solutions will increase [31].

\section{Conclusion}

In conclusion, it should be noted that further dynamic development of the DLT can contribute to a greater interest of policy makers in smart contracts. It seems that it depends a lot on the significant factor which is the factor of power activity, in other words, it depends a lot on people who are in power and also on influencial persons who can contribute to increasing science's participation in the study of this novelty. It should be regarded as positive that the approval of the paper to smart contract in the Code of Commercial Companies is allowed. It seems worrying that there are no indications concerning the evidential issues connected with the introduction of this type of solution. The most visible change that can be transferred into the practice of smart contracts is the contract of evidence, but its possibilities are significantly limited.

Certainly, in the context of the digital society functioning in smart city, it should be perceived positive that the contract of evidence does not apply to the entrepreneur-consumer relationship. However, the development of the smart city concept implies many other challenges to be faced. Both in terms of smart contracts as well as in terms of law.

Taking into account the participation of Poland in the structures of the EU, it seems substantial to formulate several conclusions in the form of postulates which open the discussion on smart contract under the laws of Poland:

- Poland should be active and monitor the legislative activity of the EU in the field of DLT technology.

- The EU should regulate DLT and introduce the most sustainable technology and state a technologically neutral definition of smart contracts.

- The EU should establish an office to regulate matters relating to the competence of the experts dealing with problems concerning smart contracts, and this office should solve any potential problems within the area of smart contracts.

- The Polish legislator should, in turn, examine and propose possible amendments to the Civil Law Code and the evidence law, so that it takes into account the digital nature of digital evidence.

- The provision related to contracts of evidence should be monitored in terms of its usefulness in practice and also together with the appropriate proposals, possibly extended.

\section{Competing Interests:}

None declared.

\section{Ethical approval:}

Not applicable. 
Funding:

None declared.

Acknowledgements:

Dr Janinie Grucza - for the first steps in the world of science.

\section{References:}

[1] K. Zacharzewski and M. Kłoda, "Przegląd zastosowania technologii blockchain w wymiarze sprawiedliwości w wybranych państwach", Instytut Wymiaru Sprawiedliwości, Warsaw, 2019.

[2] E. Salmerón-Manzano and F. Manzano-Agugliaro, "The Role of Smart Contracts in Sustainability: Worldwide Research Trends", Sustainability, vol. 11, no. 11, p. 3049, 2019. Available: 10.3390/su11113049 [Accessed 13 January 2020].

[3] N. Szabo, "Formalizing and Securing Relationships on Public Networks”, First Monday, vol. 2, no. 9, 1997. Available: $10.5210 /$ fm.v2i9.548.

[4] N. Szabo, "The Mental Accounting Barrier to Micropayments", Nick Szabo's Essays and Concise Tuturials, 19.

[5] V. Morabito, Business innovation through blockchain the $\mathrm{b}(3)$ perspective.

[6] V. Buterin, A next generation smart contract \& decentralized platform. 2014.

[7] J. Sklaroff, "Smart Contracts and the Cost of Inflexibility", University of Pennsylvania Law Review, vol. 166, 2017. Available: https://papers.ssrn.com/ sol3 $/$ papers.cfm?abstract_id $=3008899$. [Accessed 13 January 2020].

[8] A. Savelyev, "Contract law 2.0: 'Smart' contracts as the beginning of the end of classic contract law", Information \& Communications Technology Law, vol. 26, no. 2, pp. 116-134, 2017. Available:

10.1080/13600834.2017.1301036 [Accessed 13 January 2020].

[9] K. Künnapas, "From Bitcoin to Smart Contracts: Legal Revolution or Evolution from the Perspective of de lege ferenda?", in The Future of Law and eTechnologies, T. Kerikmäe and A. Rull, Ed. Cham: Springer International Publishing Switzerland, 2016, pp. 111-129.

[10] P. Cuccuru, "Beyond bitcoin: an early overview on smart contracts", International Journal of Law and Information Technology, vol. 25, no. 3, pp. 179-195, 2017. Available: 10.1093/ijlit/eax003 [Accessed 13 January 2020].

[11] G. Wood, "Ethereum: A secure decentralized generalized transaction ledger. EIP-150 revision", Available: http://gavwood.com/Paper.pdf [Accessed 20 March 2020].

[12] R. Unsworth, "Smart Contract This! An Assessment of the Contractual Landscape and the Herculean Challenges it Currently Presents for 'Self-executing'
Contracts", in Legal Tech, Smart Contracts and Blockchain, M. Corrales, M. Fenwick and H. Happio, Ed. Singapore: Springer Nature Singapore Pte Ltd., 2019, pp. 17-59.

[13] K. Low and E. Mik, "Pause The Blockchain Legal Revolution", International and Comparative Law Quarterly, vol. 69, no. 1, pp. 135-175, 2019. Available: $10.1017 / \mathrm{s} 0020589319000502$.

[14] E. Mik, "Smart Contracts: A Requiem”, SSRN Electronic Journal, 2019. Available: 10.2139/ssrn.3499998 [Accessed 13 January 2020].

[15] R. Herian, "Legal Recognition of Blockchain Registries and Smart Contracts", in Blockchains and smart contracts legal and regulatory framework, Paris, France, 2018.

[16] E. Mik, "Smart contracts: terminology, technical limitations and real world complexity", Law, Innovation and Technology, vol. 9, no. 2, pp. 269-300, 2017. Available: 10.1080/17579961.2017.1378468 [Accessed 13 January 2020].

[17] E. Till, O znaczeniu prawnem automatu. Lviv: E. Winiarz, 1900.

[18] D. Szostek, Blockchain and the Law, 1st ed. BadenBaden: Nomos Verlagsgesellschaft Mbh \& Co.

[19] E. Mik, "Smart Contracts: A Requiem", SSRN Electronic Journal, 2019. Available: 10.2139/ssrn.3499998 [Accessed 13 January 2020].

[20] The European Union Blockchain Observatory and Forum, "Legal and Regulatory Framework of Blockchains and Smart Contracts", The European Union Blockchain Observatory and Forum, 2019.

[21] G. Governatori, F. Idelberger, Z. Milosevic, R. Riveret, G. Sartor and X. Xu, "On legal contracts, imperative and declarative smart contracts, and blockchain systems", Artificial Intelligence and Law, vol. 26, no. 4, pp. 377-409, 2018. Available: $10.1007 /$ s10506-0189223-3 [Accessed 13 January 2020].

[22] Закон о внесении изменений в части первую, вторую и статью 1124 части третьей ГражАанского кодекса Российской Федерации, по. 424632-7. Moscow: Государственная Аума Фелерального Собрания Российской Федерации, 2019.

[23] T. Barton, H. Haapio, S. Passera and J. Hazard, "Successful Contracts: Integrating Design and Technology", in Legal Tech, Smart Contracts and Blockchain, M. Corrales, M. Fenwick and H. Haapio, Ed. Singapore: Springer Nature Singapore Pte Ltd., 2019.

[24] Evidence Act, vol. 97. Singapore: Singapore Government, 1983.

[25] Rządowy projekt ustawy o zmianie ustawy - Kodeks spółek handlowych oraz niektórych innych ustaw, no. 2019, 3236. Warsaw: Sejm Rzeczypospolitej Polskiej, 2019 . 
[26] Kodeks Postępowania Cywilnego. Warsaw: Sejm Rzeczypospolitej Polskiej, 1964.

[27] M. Kõlvart, M. Poola and A. Rull, "Smart Contracts", in The Future of Law and eTechnologies, T. Kerikmäe and A. Rull, Ed. Cham: Springer International Publishing Switzerland, 2016, pp. 133-145.

[28] K. Werbach and N. Cornell, "Contracts Ex Machina”, Duke Law Journal, vol. 67, no. 2, pp. 313-381, 2017. Available: https://scholarship.law.duke.edu/ cgi $/$ viewcontent.cgi? article $=3913 \&$ context $=\mathrm{dlj}$. [Accessed 13 January 2020].

[29] J. Sun, J. Yan and K. Zhang, "Blockchain-based sharing services: What blockchain technology can contribute to smart cities", Financial Innovation, vol. 2, no. 1, 2016. Available: 10.1186/s40854-016-0040-y [Accessed 14 January 2020].

[30] M. Solarte-Vasquez, N. Järv and K. Nyman-Metcalf, "Usability Factors in Transactional Design and Smart Contracting", in The Future of Law and eTechnologies, T. Kerikmäe and A. Rull, Ed. Cham: Springer International Publishing Switzerland, 2016, pp. 149-174.

[31] M. Bułkowski, email answer for "Wniosek o dostęp do informacji publicznej dot. CoperniCoin/Request for access to public information concerning CoperniCoin" sent on 17 December 2019 to Marshal Office of the Warmia and Mazury Region. 